\title{
Research on construction of the grass-roots teaching organization within university based on the theory of CSM
}

\author{
Zhang Hongjing \\ School of Economics and Management \\ Northeast Dianli University \\ Jilin, China \\ e-mail: zhanghongjing001@sina.com
}

\author{
Lin Zhouzhou \\ School of Economics and Management \\ Northeast Dianli University \\ Jilin, China \\ e-mail: 627609305@qq.com
}

\author{
Li Shengnan \\ School of Economics and Management \\ Northeast Dianli University \\ Jilin, China \\ e-mail:1419910719@qq.com
}

\begin{abstract}
As the core of grass-roots teaching organization, university teachers represent a high level of intellectual groups. University teachers' development is more particularity. Existing literature on the grass-roots teaching organization have ignored the relationship between teachers within the organization. The construction of grass-roots teaching organization is not fully improved. Based on the introduction of CSM theory, the article has analyzed the complexity of grass-roots teaching organization. Then from the perspective of the relationship between teachers and organizations, the article proposed four progressive layers measures which included establishing overall concept, achieving resource innovation, introducing competition mechanism and setting up the group norms. These measures lay the foundation to integrate resources and complete goals for organization. They will be conducive to perfect the construction of grass-roots teaching organization.
\end{abstract}

Keywords-CSM theory; grass-roots teaching organization; complexity; university teachers

\section{INTRODUCTION}

For a long time, the grass-roots teaching organization plays an important role in strengthening the basic teaching construction, expanding teaching body and organizing teaching research. It undertakes teaching, scientific researches and services. It provides an important guarantee in improving the teaching abilities, realizing academic innovation and promoting the cultivation of talents. With the advent of knowledge economy times, the country pays more attention to the development of higher education. Under this background, universities have to accelerate the pace of reform in order to raise the school-running level, such as expanding functions of university, applying for doctoral degree and building innovative university. However, the construction of grass-roots teaching organization is not enough, relatively backward and showing a phenomenon of gradual decline. The previous grass- roots teaching organization can not meet needs of the new situation that we must reform and construct it. Only by increasing some functions matching other departments, can we realize the goal of improving teaching quality and comprehensive strength within university. In 2012, the Ministry of Education released a number of views on improving the quality of higher education. The twenty-seventh also specifically pointed out that we must improve teachers' academic level and teaching abilities, improving grass-roots teaching organization which contains staff room and teaching team. These factors make the construction of the grass-roots teaching organization within university become a hot spot of research.

Du Binheng and Chen Yuchen (2012) analyzed the urgency about strengthening the innovation of the grass-roots teaching organization system. He put forward to teaching engagement system. It contained that constructing a teaching and reformed center, adapting to the working mechanism and reforming performance evaluation system of teachers ${ }^{[1]}$. Yu Baochun and Huang Yaoyuan (2013) revolved the grass-roots teaching organization within provincial universities to study the combination of teaching management system and practice. They also explored further the building about teaching management team to provide a theoretical basis and practical framework for the grass-roots teaching organization studying ${ }^{[2]}$ Gao Weiyi (2013) pointed out that establishing a sound set of objective, reasonable university job evaluation system about grass-roots organizations was the most important work in university. On the basis of analyzing the current situation of grass-roots organizations evaluation, combined with the DEA model and method, he established an evaluation system grassroots organizations working in university ${ }^{[3]}$. The above documents were main focus on studying the grass-roots teaching organization system, taking a big-picture view on organizational system, organizational forms, organizational 
functions. They set up a framework for grass-roots teaching organization, but ignored the university teachers' particularity as a subject in grass-roots teaching organization. University teachers represent a high level of intellectual groups. It is complex that thinking mode, development environment, training process within university teachers so that the construction of grass-roots teaching organization has also complexity. If we just study the grass-roots teaching organizations through building the organizational system, ignoring the personal development of teachers within organization, the impact of internal and external environment, our research result will be relatively simple. Therefore, this article is based on the problems identified and combined with the CSM theory. In systems thinking as a guide, it makes some recommendations about the grass-roots teaching organization reform. They are conducive to perfect the construction of grass-roots teaching organization.

\section{THE CSM THEORY SUMMARY}

\section{A. Meaning of CSM theory}

According to the new thinking mode and new observation problem, CSM is based on the complex science and management science to fusion and development, studying complexity system which included management thinking, management theory and management methods ${ }^{[4]}$. The theory holds that social system is a complicated system which has the ability of thinking. It has self-organization, self-adaptability and dynamic.

The thinking mode of CSM is systematic thinking. Systematic thinking is holistic view as the core, cyclic see cause and effect. It passes through systems thinking, structured thinking and integrated systems resources to make the system competitive. It includes systems thinking as a thinking way about research complex problem, cyclic see cause and effect as an observation angle of complex issues, in a structured and modular thinking as a thinking process to analyze complex problems ${ }^{[5]}$.

\section{B. The CSM theory}

The CSM theory includes the overall outlook, the new outlook on resources, the theory of interaction, the order and disorder and the theory of integration.

The overall outlook considers that the organization should stand in the perspective of the whole system. And the whole system is the starting point and destination of the organization, including the new perspective of parsing problem, the non additive law and the utility maximization. The new outlook on resources considers that besides natural resources, social resources, cultural resources, system resources, purchasing power resources and so on also are very important resources. And new resources can be obtained by creating and developing. The theory of interaction considers that under a certain conditions of time and space, members can make positive changes in system through interaction with each other. The order and disorder theory considers that the evolution of organization is an intermittent and spiraling process that from disorder to order and from order to disorder. Integration is to make reasonable adjustments to the existing resources, realizing the organic combination, pursuing the optimization of resource overall structure and the maximization of overall effectiveness, achieving the goal "the whole is greater than the sum of its parts.

\section{COMPLEXITY ANALYSIS ABOUt CONSTRUCTION OF THE GRASS-ROOTS TEACHING ORGANIZATION}

\section{A. The complexity of organizational subject}

As the subject of grass-roots teaching organization, university teachers represent a high level of intellectual groups. It is complex that thinking mode, development environment, training process within university teachers so that the construction of grass-roots teaching organization has also complexity ${ }^{[6]}$. On the one hand, at present, there is a problem that universities teachers have no strong or missing belongingness, lead to university teachers' sense of responsibility and honor lost. If university teachers only work mentality to deal with work, this is not conducive to play the role of grass-roots teaching organization. The phenomenon with university teachers' professional characteristics, human characteristics and the reform of university are inseparable. On the other hand, teacher conflict is not conducive to the stability of grass-roots teaching organization. This conflict refers to the process that opposition and divergence in goals, concepts, values, affections and interests appear between different team members, team members and organization, team and organization ${ }^{[7]}$, including interpersonal conflict, cognitive conflict, goal conflict and psychological conflict.

\section{B. The complexity of organizational surrounding}

1) The complexity of internal surrounding: In general, the same organization of teachers with professional and research directions are similar which should be able to more communication and learning. But in fact, there are competitions among teachers, leading a organization of internal conflict. The object of conflicts can be interests, values, goals, personality and so on in many aspects. For instance, now job promotion and job classification of college teachers are not very reasonable. Performance appraisal system is not perfect and the annual number of job classification is also limited. Then these interests make the same team of teachers produce some competitions. A person's thinking and ability are limited and they can not cover everything. What's more, teaching and researching activities have their own way in long term so that there are some negative phenomenon appearing, such as the emergence of decentralized activities and cohesion not strong. Not only hinder teachers' abilities to improve, these phenomenon but are not conducive to the healthy development of teacher relationships. When differences appear, it is likely to generate conflicts.

2) The complexity of external surrounding: Through a long run and integrations, the various organizations have formed their own organizational structure .Then members get a sense of belonging and presence. While there is a competition within teams, between different teams have more competitive as limited resources and other factors exist. 
Although it will temporarily enhance cohesion within the team, but organizational construction is very unfavorable in the long term and holistic. In order to assess and encourage departments to work hard, motivate teachers to carefully complete the teaching contents, open up new areas of academic research, raising awareness and strength in the school community. It is usually a corresponding incentive. In annual awards, some teachers achieve ceremony on specific sectors, individuals honor and money. And university resources will be given priority so that the competition formed between teams. For the benefit of their respective teams, different teams of teachers hostile and rarely deeper exchanges in teaching and academic. They even to hide their own research team to foreign. The same branch of the teaching is no strict dividing line in the academic, issues that often require the other research process and supports. It will help to better and faster in scientific research. Their abilities are limited. In the case of a hostile, follow-up studies are likely to be inadequate. The role of academic exchange becomes stretched, there may be provided an opportunity to manufacture conflict.

\section{INSPIRATION OF CSM THEORY TO CONSTRUCTION OF THE GRASS-ROOTS TEACHING ORGANIZATION WITHIN UNIVERSITY}

\section{A. Set up the overall concept and maintain the internal stability of organization}

The overall outlook theory tells us that the organization should stand in the perspective of the whole system. And the whole system is the starting point and destination of the organization. Due to the complexity of the organization subject and the organization environment, the internal members of the grass-roots teaching organization are prone to conflict, which is not conducive to the stability of organization. We must set up the overall concept, standing in the height of the overall concept, maintaining the stability of the organization. There are two sides following. Firstly, adhere to the principle of effective leadership. Any organization needs a leader to lead. The construction of grass-roots teaching organization within universities is different from other general organizations. The responsible person must have high attainments in the teaching and academic aspects, clearly the present situation of the subject and he can grasp the development direction and trend about educational reform. He has its own unique perspective in teaching reform, teaching system, teaching content and formulates some plans for the development of this discipline. He has strong organizational leadership skills and he is good at dealing with the relationship between members of the organization. What's more, he is widely recognized by organization members. Secondly, strengthen the echelon construction of teachers' team. We should give full play to the role of the grass-roots teaching organization in the construction of teachers, strictly and help young teachers to be able to work independently. We guarantee that the structure of the teachers' team is reasonable and the echelon is strong so that the grassroots teaching organization can develop towards sustainable ecosystem.

\section{B. Achieve resource innovation and provide a steady stream for organization}

The grass-roots teaching organization has a lot of resources, including cultural resources, system resources, high level of human resources. We should pay more attention to these resources and use them. Only by the extension of resources function and the creation of new resources, can we provide a steady stream of power for the organization. The organization can stand out in the competition.

1) Develop a core culture of solidarity and cooperation: Firstly, we can set up the principle of people-oriented. As the core of grass-roots teaching organization, university teachers also has the particularity. We should respect the existence of teaching individuality and commonality and implement the concept of equal members. We make teachers get care, respect and trust in the unit. They can feel the harmonious and comfortable atmosphere. Secondly, we can build a platform for teachers to exchange and study. The cultivation of belongingness depends on the communication between people and people. For the characteristics of university teachers' dispersion, we can take a combination between actual platform and virtual platform. Through regular or irregular grass-roots teaching activities, we can promote exchanges of internal teacher and develop a core culture of solidarity and cooperation.

2) Strengthen cooperation among organizations: Under the new situation, the organization is no longer a complete independent unit. It is realized that the integration and innovation of organization structure through the cooperation and the influence of among organizations. The "common needs" of organizations is good at promoting cooperation and achieving a win-win. We know that carrying out teaching research, promoting the teaching reform, undertaking the comprehensive project need to cooperate among the teachers or the organizations. The differences and interdisciplinary of the professional knowledge have decided that the grass-roots teaching organization is willing to carry on the deep level discussion and the exchange with the other different discipline organization. The cooperation of different subjects in teaching organizations is becoming one of the best ways to reduce cost, undertaking large scale integrated projects and playing a role in cross discipline.

\section{Introduce competition mechanism and promote the interaction of organization members}

Interaction is a dynamic process, which is the interaction between different individuals in the same situation so that makes each other and systems change. This change is the emergence. And it is a new quality of the original individual or system, that is, the individual or the system has not been appearing the design, structure and characteristics ${ }^{[8]}$. CSM assumes that people are complexity intelligent people. It is undoubted that university teachers are a vivid representation. When there is competition between organizations, the organization's interests and honor are challenged. In order to maintain the reputation and interests about their own teams, they will cooperate in good faith and strengthen solidarity. University teachers are highly qualified representatives and communicators, having self-realization and self-affirmation of 
desire. When faced with threatened of the team in status and interests, they will soon realize the importance of unity and contribute their power. Teachers can enhance mutual cooperation and cohesion, reducing conflicts.

We can find four aspects of introducing competition. Firstly, we can provide system support. We ensure that teachers can be based on system when they start title evaluation or interest distribution. Secondly, through select outstanding grass-roots teaching organization, we can fully mobilize the enthusiasm of teachers from different organizations and enhance teacher's sense of honor and disgrace. They will compete and maintain for the organization honor to work hard. Thirdly, university can hold teaching projects, encouraging grass-roots teaching organization to undertake projects. The quality and results of projects related to the awards about organization and individual.

\section{Establish group norms and realize consolidate of order and disorder}

We should give full play to the role of institutional resources to achieve a unified of tangible system and intangible system. Within the organization, "too much conflict" is often because the members of their own position and the dependencies between them which are not a clear understanding. Then it requires the establishment a unified norms of group. When individuals face their own standards different with others, they will be re-established by the interaction of a standard. The standard is quite solid and reliable in the population. The members will be adjusted their behavior according to this standard. It is the standard of identity, agreed with one another then form a whole. Under the premise with common aspirations, organizational members contribute their knowledge and wisdom. In the process of building exploration Fig., we can through dialogue and other means to digest and absorb our ideas. Then we can reach a consensus understanding of the issues and make decisions, which guide the organization members to take action to achieve common goals ${ }^{[9]}$.

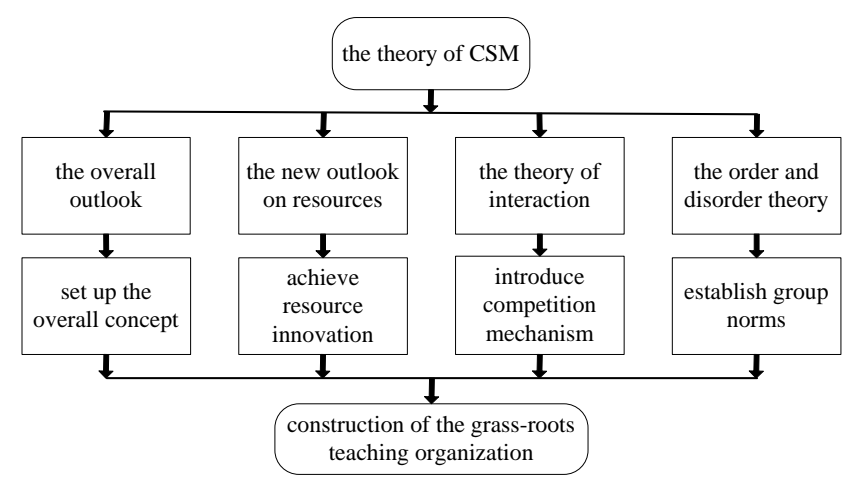

Fig. 1 the four measures based on the theory of CSM

In summary, the four measures are carried out in different angles (Fig. 1). Setting up the overall concept is the perspective of grass-roots teaching organization. Achieving resources innovation is the steady stream of power. Introducing competition mechanism is a way which the grass-roots teaching organization enhance the overall strength.
Establishing group norms is holding up the state of grass-roots teaching organization. On this basis, we can use the idea of CSM integration theory and establish a goal which is the construction of excellent grass-roots teaching organization. Then we analyze the resources needed to achieve this goal, standing on a height of the overall concept, picking up the resources which may achieve the goal. And we begin to collate these resources. Finally, according to available resources and what resources are required, we explore some ways to achieve the integration of target resources. We can achieve the integrated targets which include realizing integration, creating new resources, enhancing the capacity of resources to create wealth and change the resource output for the integration objectives.

\section{CONCLUSION}

From a theoretical point of view, the harmonious relationship between the members and the organization is the important guarantee for the construction of grass-roots teaching organization within universities. It is not enough that the reform and innovation of the grass-roots teaching organization only through the organization system. Based on the CSM theory, this article analyzed the complexity of grass-roots teaching organization and combined with the five theory of CSM. Some suggestions are put forward for the problems and the new reform ideas in the construction of grass-roots teaching organization within universities. The drawback of this study is more from the psychological point of view to study grass-roots teaching organization and this article has not cited some cases to describe. Because different grass-roots teaching organizations have their own features, we need to analyze specific issues. I suggest that further studies can make the Basic Pilot. According to their own characteristics, we can organize the reform and construction of grass-roots teaching organization, including how to build a flexible evaluation system and how to achieve maximization of cooperation utility. The actual implementation of management can provide a reference for the construction of grass-roots teaching organization within university.

\section{REFERENCES}

[1] Du Binheng and Chen Yuchen. The innovation of grass-roots teaching organization in high level research university [J]. Higher Agricultural Education, 2012(3): 53-55. (In Chinese)

[2] Yu Baochun and Huang Yaoyuan. Research and Practice on the construction of local grass-roots teaching organization under the new situation [J]. Li Lun Dao Bao, 2013(1): 51-56. (In Chinese)

[3] Gao Weiyi. Based on DEA the evaluation model about the construction of the grass-roots organization within university $[\mathrm{J}]$. Pioneering with science \& technology monthly, 2013(10): 113-114. (In Chinese)

[4] Xu Xusong and $\mathrm{Wu}$ Qiang. The frontier of management science: complexity science management [N]. Guangming daily, 2005.05.10(10). (In Chinese)

[5] Xu Xusong. Research on the frontier of management science [N]. Guangming daily, 2005.9.20(8). (In Chinese)

[6] Cheng Siwei. Scientific exploration of complexity (a collection of papers) [C]. Beijing: democracy and construction press, 1999. (In Chinese) 
[7] Wang Jie. Mechanism of team task conflicts effect on the team task performances [D]. Hangzhou: Zhejiang University, 2009(5). (In Chinese)

[8] Zheng Zhan. Cultural Creative Interaction View Based on the CSM Interaction Theory [J].Science \& Technology Progress and Policy, 2013(6):55-58. (In Chinese)
[9] Lan Xiangchun. Introduction to Complexity Science Management [J]. Journal of Wuhan Electric Power Technical College, 2010(12):58-61. (In Chinese) 